\title{
ESTUDIO QUÍMICO BROMATOLÓGICO DEL FRUTO DEL NÍSPERO DE PALO (Mespilus germanica L.), PROCEDENTE DE AYACUCHO
}

\author{
Bromatological chemical study of the fruit of the níspero de palo (Mespilus germanica l.) from \\ Ayacucho \\ Yanet Vargas R, Erika Pisfil E, Nelson Bautista C y Gladys C. Arias A. \\ Laboratorio de Bromatología. Facultad de Farmacia y Bioquímica. Universidad Nacional Mayor de San Marcos
}

\section{RESUMEN}

Se realizó la determinación químico bromatológica de Mespilus germanica L. (Níspero de palo), procedente de la provincia de Vilcashuamán, Región Ayacucho - Perú. De la evaluación se obtuvo los siguientes resultados, expresados en gramos por 100 g de muestra fresca: 73,13 de agua, o,57 de proteína total; 0,41 de extracto etéreo; 23,04 de carbohidratos; 0,63 de cenizas; 2,22 de fibra cruda; 3,82 de azúcares reductores; 12,06 de azúcares reductores totales. Minerales, expresados en miligramos por $100 \mathrm{~g}$ de muestra fresca: 76,71 de sodio; 265,25 de potasio; 24,03 de magnesio; 92,42 de calcio; 28,48 de fósforo; 2,02 de fierro; 0,76 de cinc; 2,85 de cobre. Asimismo, 14,06 miligramos de vitamina $C$ en $100 \mathrm{~g}$ de muestra fresca.

Palabras clave: Níspero de palo, níspero del monte, nispolero, níspero europeo, Mespilus germanica L.

\section{SUMMARY}

We did the chemical bromatological determination of Mespilus germánca L. (Nispero de palo) from Vilcashuaman province, Ayacucho region - Peru. The evaluation had the following results expressed in grams per $100 \mathrm{~g}$ of fresh sample; 73,13 of water; 0,57 for total protein; 0,41 of ether extract; 23.04 of carbohydrates, 0.63 of ash ; 2.22 of raw fiber; 3,82 of reducing sugars; total reducing sugars 12,06. Minerals, expressed in mg per 10og fresh sample: 76,10f sodium, 266, 25 of potassium; 24, 03 of magnesium; 92, 42 of calcium; 28, 48 of phosphorus; 2.02 of iron; o.76 of zinc; 2, 85 of copper. Also, 14.06 milligrams of vitamin $C$ per $100 \mathrm{~g}$ of fresh sample.

Keywords: Níspero de palo, níspero de monte, nispolero, níspero europeo, Mespilus germanica L.

\section{INTRODUCCIÓN}

os diversos pisos ecológicos del Perú hacen propicio el crecimiento de una gran variedad de plantas alimenticias. Una de estas, que crece y se adapta muy bien a tierras áridas y secas de nuestro territorio es Mespilus germanica L., planta comúnmente conocida en muchos lugares de nuestro país como: níspero, nispolero, níspero de palo, níspero europeo, níspero del monte o níspero andino ${ }^{(1)}$. Esta planta, según las referencias, es originaria de Europa, en la actualidad crece en casi todos los valles interandinos del Perú y en muchos países en los cuales se ha estudiado se le ha dado mayor importancia con fines medicinales ${ }^{(2,3)}$. Es un árbol que crece de 3 a $5 \mathrm{~m}$ de altura, es muy resistente a sequías, heladas, enfermedades y condiciones ambientales extremas; tiene un fruto que en su óptima maduración tiene sabor y aroma agradables ${ }^{(4)}$.
En nuestro país, el fruto es consumido principalmente en forma directa como fruto fresco, pero en algunos lugares, como la provincia de Vilcashuamán, Región Ayacucho, se elaboran productos derivados como: níspero en almíbar y agua de níspero obtenida mediante el licuado de la pulpa del fruto o por simple cocción; en todos los casos, los productos obtenidos son de sabor y olor agradables. La temporada de producción del fruto en Vilcashuaman se extiende de junio a octubre, período soleado en esta zona del país con escasas precipitaciones ${ }^{(5)}$. De cada planta se obtiene aproximadamente de 500 a $700 \mathrm{Kg}$ de fruto, con cosechas que comprenden varias etapas que se extienden a lo largo de los meses mencionados.

Existe una gran confusión cuando se habla sólo del níspero; así, en la Costa se refieren al níspero japonés que es otra especie originaria del continente asiático, mientras que en la Sierra se refieren al níspero de palo. Estas plantas, a pesar que pertenecen a la misma 
familia, rosáceas, tienen diferentes característica botánicas; así por ejemplo, el fruto de níspero japonés tiene mayor contenido de agua, es más suave, en tanto el fruto de níspero de palo tiene menor contenido de agua, es más fibroso y es una planta más frondosa ${ }^{(4,6)}$. Por otra parte, el fruto de níspero de palo se caracteriza por el alto contenido de pectina ${ }^{(7)}$.

En el Perú existen estudios sobre el fruto del níspero de palo desde el punto de vista de su factibilidad para la obtención de derivados y la instalación de plantas de elaboración de conservas, pero todos estos estudios aún se encuentran en proyectos ${ }^{(8,10)}$. El níspero de palo aún no es considerado como un fruto de explotación agroindustrial por falta de estudios que permitan conocer su verdadero valor como una fruta de consumo común ${ }^{(6)}$.

Generalmente, el consumo del fruto de níspero de palo por los pobladores de la costa y Los Andes se ve influenciado por sus características organolépticas agradables, mas no por sus propiedades nutricionales ${ }^{(6)}$.

Por otro lado, en nuestro país su cultivo no alcanza fines de explotación agroindustrial como alimento. Se cultiva con fines ornamentales y la falta de difusión de información de las propiedades del fruto hace que no exista mucho interés de los habitantes para cultivarlo como una planta frutal. El cultivo de esta planta en Vilcashuamán es deficiente debido a que los pobladores no le dan los cuidados que requiere como a otros frutos más comerciales.

Con la difusión de este trabajo se busca, de manera indirecta, revalorar esta planta como un recurso vegetal, fomentando así el aprovechamiento al máximo de su fruto con fines alimenticios y funcionales; promover su cultivo permanente como planta frutal para que pueda desarrollarse una agroindustria sostenible. Asimismo, complementar con información sobre su valor nutricional y estudios de factibilidad para la obtención de diversos derivados ${ }^{(11,12)}$.

Por consiguiente, el presente trabajo tuvo como objetivo determinar el valor nutricional del fruto de níspero de palo a fin de otorgarle la importancia que le corresponde en las zonas de procedencia y otras del país.

\section{MATERIALES Y MÉTODOS}

\section{Recolección, transporte y conservación de la muestra}

La muestra en estudio se recolectó en la provincia de Vilcashuamán, ubicada a $117 \mathrm{Km}$ al sureste de la ciudad de Huamanga, durante el mes de setiembre.

Las muestras se recolectaron en bolsas de polietileno y se transportaron tomando precauciones para no golpear los frutos durante el transporte; además se conservaron en refrigeración.

\section{Preparación de la muestra}

Para realizar el estudio químico bromatológico, se seleccionaron frutos con características homogéneas, como: óptima maduración (pintones), los cuales se caracterizan por un color anaranjado intenso, tamaño homogéneo y libre de daño físico. Luego se separaron las hojas y las ramas que contenían algunos frutos. La parte estudiada del fruto fue la pulpa; se separaron la cáscara y las semillas, y luego se homogenizó la muestra para los análisis correspondientes.

\section{Determinaciones analíticas}

El contenido de agua, proteína total, extracto etéreo, ceniza y fibra cruda, fueron determinados utilizando los métodos de la AOAC ${ }^{(13)}$. El factor utilizado para calcular proteína fue 6,25. Los carbohidratos fueron obtenidos por diferencia, es decir sustrayendo de 100 la suma de agua, proteína total, extracto etéreo, ceniza y fibra cruda. Los azúcares reductores directos y totales fueron determinados utilizando el método de Lane y Eynon de la AOAC (13). Los minerales fueron determinados utilizando los métodos analíticos por espectrofotometría de Absorción Atómica ${ }^{(14)}$, excepto fósforo el cual fue determinado por el método espectrofotométrico (13). La vitamina $C$ fue determinada por el método de titulación con el 2,6-diclorofenolindofenol ${ }^{(13)}$. La determinación de $\mathrm{pH}$ y acidez total se realizó utilizando los métodos de Egan H. ${ }^{(15)}$ y AOAC ${ }^{(13)}$, respectivamente. Para la determinación del valor calórico se utilizó el método de USDA (United States Department of Agriculture) ${ }^{(6,17)}$.

\section{RESULTADOS}

La concentración de vitamina $C$ en 100 gramos de muestra fresca del fruto de níspero de palo (Mespilus germanica $L$.) fue de 14,06 miligramos.

\section{DISCUSIÓN}

En la actualidad hay pocos trabajos realizados acerca del níspero de palo, los estudios revisados son principalmente sobre níspero japonés que es el fruto 
Tabla 1. Composición químico bromatológica en 100 gramos del fruto de níspero de palo (Mespilus germanica $L$.).

\begin{tabular}{lcc}
\hline Descripción & $\begin{array}{c}\text { Muestra fresca } \\
\text { (gramos) }\end{array}$ & $\begin{array}{c}\text { Muestra seca } \\
\text { (gramos) }\end{array}$ \\
\hline Agua & 73,13 & -- \\
Proteína total & 0,57 & 2,12 \\
Extracto etéreo & 0,41 & 1,53 \\
Carbohidratos & 23,04 & 85,75 \\
Cenizas & 0,3 & 2,34 \\
Fibra cruda & 2,22 & 8,26 \\
Acidez titulable * & 0,88 & 3,28 \\
A.R.D. (g/\% glucosa) ** & 3,82 & 14,25 \\
A.R.T. (g/\% glucosa) *** & 12,06 & 44,98 \\
Energía total (Kcal/100g de muestra) & 88,51 & 330,13 \\
\hline
\end{tabular}

* En forma de ácido cítrico $\quad{ }^{* *}$ A.R.D: Azúcares reductores directos $\quad * * *$ A.R.T: Azúcares reductores totales

Tabla 2. Contenido de minerales en 100 gramos del fruto de níspero de palo (Mespilus germanica $L$.) en muestra fresca y muestra seca.

\begin{tabular}{ccc}
\hline Minerales & $\begin{array}{c}\text { Muestra fresca } \\
\text { (miligramos) }\end{array}$ & $\begin{array}{c}\text { Muestra seca } \\
\text { (miligramos) }\end{array}$ \\
\hline Fósforo & 28,48 & 105,99 \\
Fierro & 2,02 & 7,52 \\
Sodio & 76,71 & 285,49 \\
Potasio & 265,25 & 987,16 \\
Magnesio & 24,03 & 89,43 \\
Calcio & 92,42 & 343,95 \\
Cinc & 0,76 & 2,83 \\
Cobre & 2,85 & 10,61 \\
\hline
\end{tabular}

más conocido y comercial.

El contenido de agua encontrado en la muestra fue de $73,13 \%$, lo cual se encuentra muy cercano al resultado hallado por Leandres ${ }^{(12)}$ que fue $72,30 \%$; las diferencias pueden deberse al tipo de clima, suelo, cantidad de precipitaciones pluviales y la temporada de recolección. En nuestro estudio la recolección se efectuó en invierno (primeros días de setiembre) ya casi iniciando la primavera, que es la estación con días soleados en la provincia de Vilcashuamán.

El contenido de carbohidratos hallados en la muestra fresca fue de $23,04 \%$, lo cual constituye uno de los componentes que se encuentra en mayor porcentaje, dicho valor se encuentra ligeramente por encima del valor hallado por Leandres ${ }^{(12)}$, que fué de $19,87 \%$; esto podría deberse al grado de madurez de la fruta y las condiciones ambientales.

El contenido del extracto etéreo en la muestra fue de $0,41 \%$, resultado ligeramente distante al o,29\% obtenido por Leandres ${ }^{(12)}$. La diferencia puede deberse al método usado para su cuantificación. El níspero de palo es un fruto con alto contenido de aceites esenciales a lo que se debe su olor muy agradable, en este estudio se tomaron las precauciones necesarias para evitar su pérdida durante la cuantificación del extracto etéreo.

El contenido de fibra cruda encontrado fue de $2,22 \%$, valor cercano al 2,62\% reportado por Leandres (12). Como se puede observar es un valor considerable, lo que confirma la consistencia fibrosa del fruto. 
El resultado obtenido de proteína total en la muestra fue de o,57\%, lo cual se encuentra muy por debajo del 2,38\% hallado por Leandres ${ }^{(12)}$.

La vitamina $C$ encontrada en la muestra fue de 14,06 mg por 100 gramos de muestra fresca, valor que no se puede comparar porque no hay estudios que mencionen el contenido de esta vitamina; sólo podemos hacer una comparación con 13,80 y 12,00 mg por 100 gramos, reportados por Ludeña ${ }^{(8)}$ y Collazos ${ }^{(18)}$, respectivamente, para el níspero japonés.

La variación en el contenido de vitamina $C$ depende de las variedades del fruto, las partes del fruto, grado de madurez, cantidad de radiación solar y precipitaciones ${ }^{(5)}$. El valor de la vitamina $C$ hallado es menor en comparación con los cítricos; sin embargo, es una buena fuente, sobre todo en aquellos lugares en donde el consumo de cítricos es pobre y, por lo tanto, el níspero de palo puede ser una buena alternativa como fruta fresca o procesada.

En cuanto a los minerales expresados en $\mathrm{mg}$ por 100 gramos de muestra, se encuentran en mayor cantidad: potasio 265,2 , calcio 92,42 , fósforo 28,48 y magnesio 24,03. El cinc 0,76 y fierro 2,02, a pesar de encontrarse en menor porcentaje, constituyen cantidades importantes en comparación a los requerimientos diarios ${ }^{(19,20,21)}$. El contenido de cobre 2,85 hallado en 100 gramos de muestra, no sólo llega a cubrir las necesidades requeridas $(2,0 \mathrm{mg})$, sino que la sobrepasa, por lo tanto, el fruto de níspero de palo es una fuente muy importante de este mineral. No se pueden hacer comparaciones de todos los minerales estudiados, debido a que no existen referencias cuantitativas anteriores, algunos autores los mencionan sólo cualitativamente.

\section{CONCLUSIONES}

La composición química bromatológica de Mespilus germánica L. (Níspero de palo), procedente de la provincia de Vilcashuamán, región Ayacucho (Perú) es de 73,13; 0,57; 0,41; 23,04; 0,63; 2,22; 3,82 y de 12,06 de agua, proteína total, extracto etéreo, carbohidratos, cenizas, fibra cruda, azúcares reductores y azúcares reductores totales, respectivamente por cada 100 gramos de muestra.

También contiene 76,$71 ; 265,25 ; 24,03 ; 92,42$; 28,$48 ; 2,02 ; 0,76 ; 2,85$ de sodio, potasio, magnesio, calcio, fósforo, fierro, cinc y cobre respectivamente por cada 100 gramos de muestra. Además de 14,06 miligramos de vitamina $C$ en $100 \mathrm{~g}$ de muestra.

\section{REFERENCIAS BIBLIOGRÁFICAS}

1. Venegas M. Estudiode Pre-factibilidad para la instalación de una planta de envasado de pera (Pyrus communis) y Níspero (Mespilus germanica). Universidad Nacional de San Cristóbal de Huamanga. Ayacucho, 2005.

2. Cabieses F. Apuntes de medicina tradicional. Consejo Nacional de Ciencia y Tecnologia. CONCYTEC. Lima, 1993.

3. Revista Consumer Eroski. Boletin Julio, 2004. [En línea] Disponible en: URL <http://www.consumer.es/web/es/ alimentacion/aprender_a_comer_bien/complementos_ dietéticos>. [Acceso: 30/o6/o7].

4. La Revista Digital de la Sierra Baza, Edición mensualañoVII-No 78-Diciembre 2005, El Níspero de Monte o de Invierno (Mespilus germánica) [En línea] [Acceso: 11/11/o6]. Disponible en <http://www.sierradebaza.org/ principal_05-12/notic1_05-12.htm>.

5. Bautista N. Estudio Químico - Bromatológico y elaboración de néctar de aguamiel de Agave americana $L$. (maguey) procedente de Ayacucho. Tesis para optar al título profesional de Químico Farmacéutico. Facultad de Farmacia y Bioquimica, Universidad Nacional Mayor de San Marcos. Lima, 2006.

6. Tamaro D. Tratado de Fruticultura. 4ta ed. Editorial Gustavo Guilli. Barcelona, 1986.

7. Cavero E. La Extracción de pectina a partir de níspero de palo. Tesis para optar el título de Químico Farmacéutico. Universidad Nacional de San Cristóbal de Huamanga. Ayacucho, 1990.

8. Ludeña U. Factibilidad Técnica de procesamiento del Nispero. Tesis para optar el título de Ingeniero Alimentario. Universidad Nacional Agraria La Molina. Lima, 1986.

9. Taype F. Estudio de Pre-factibilidad para la instalación de una planta de elaboración de conservas de níspero (Mespilus germanica) en Andahuaylas. Tesis para optar el título de Ingeniero Alimentario. Universidad Nacional de San Cristóbal de Huamanga. Ayacucho, 2004.

10. Palomino F. Estudio Tecnológico para la Producción de conserva de níspero (Mespilus germanica). Tesis para optar el título de Ingeniero Alimentario. Universidad Nacional de San Cristóbal de Huamanga. Ayacucho, 2000.

11. Sueldo C. Costos acumulativos en la producción industrial del Níspero en el Valle del Mantaro. Universidad Nacional del Centro del Perú. Huancayo, 1984.

12. Leandres M. Estudio tecnológico para la elaboración de mermelada mixta de maca (Lepidium meyenii, Walpers) y níspero (Mespilus germanica). Tesis para optar al título de Ingeniero Alimentario. Universidad Nacional de San Cristóbal de Huamanga. Ayacucho, 2000.

13. AOAC. Association of Official Analytical Chemist; Official Methods of Analysis. USA, 2005.

14. Skoog L. Análisis instrumental. Editorial Mc Graw Hill. 
Zaragoza, 1993.

15. Egan H. Kirt R. Sawyer R. Análisis Químico de los alimentos de Pearson. Editorial Continental S.A. México DF, 1991.

16. USDA (United States Department of Agriculture). Food and nutrient intakes of individual. Washington DC, 1982.

17. Ministerio de Salud, Instituto Nacional de Salud (MINSA, INS). Centro Nacional de Alimentación y Nutrición. Tablas peruanas de composición de alimentos. $7^{\circ}$ edición. Editorial Agrario. Lima, 1996.

18. Collazos Ch. Tablas de composición de alimentos. Editorial Acuario. Lima, 1996.

19. OPS. Organización Panamericano de la Salud. Instituto Internacional de Ciencias de la Vida, 7ma Edición. Washington DC, 1997.

20. FAO/WHO. The handbook of human nutricional requirements. FAO, Nutricional Studies. $\mathrm{N}^{\circ} 28$. Roma,1974.
21. Robinson D. Bioquímica y valor nutritivo de los alimentos. Editorial Acribia. Zaragoza, 1991.

22. FAO/WHO. The handbook of human nutricional requirements. FAO, Nutricional Studies. $\mathrm{N}^{\circ} 28$. Roma,1974.

23. Robinson D. Bioquímica y valor nutritivo de los alimentos. Editorial Acribia. Zaragoza, 1991.

Manuscrito recibido el: 23/11/2009

Aceptado para su publicación el: 23/02/2010

\section{Correspondencia:}

Nombre: Gladys Constanza Arias Arroyo

Dirección: Av. Javier Prado Oeste - № 146o - Urb.

Corpac - San Isidro - Lima

e-mail: ariasarroyo@gmail.com 